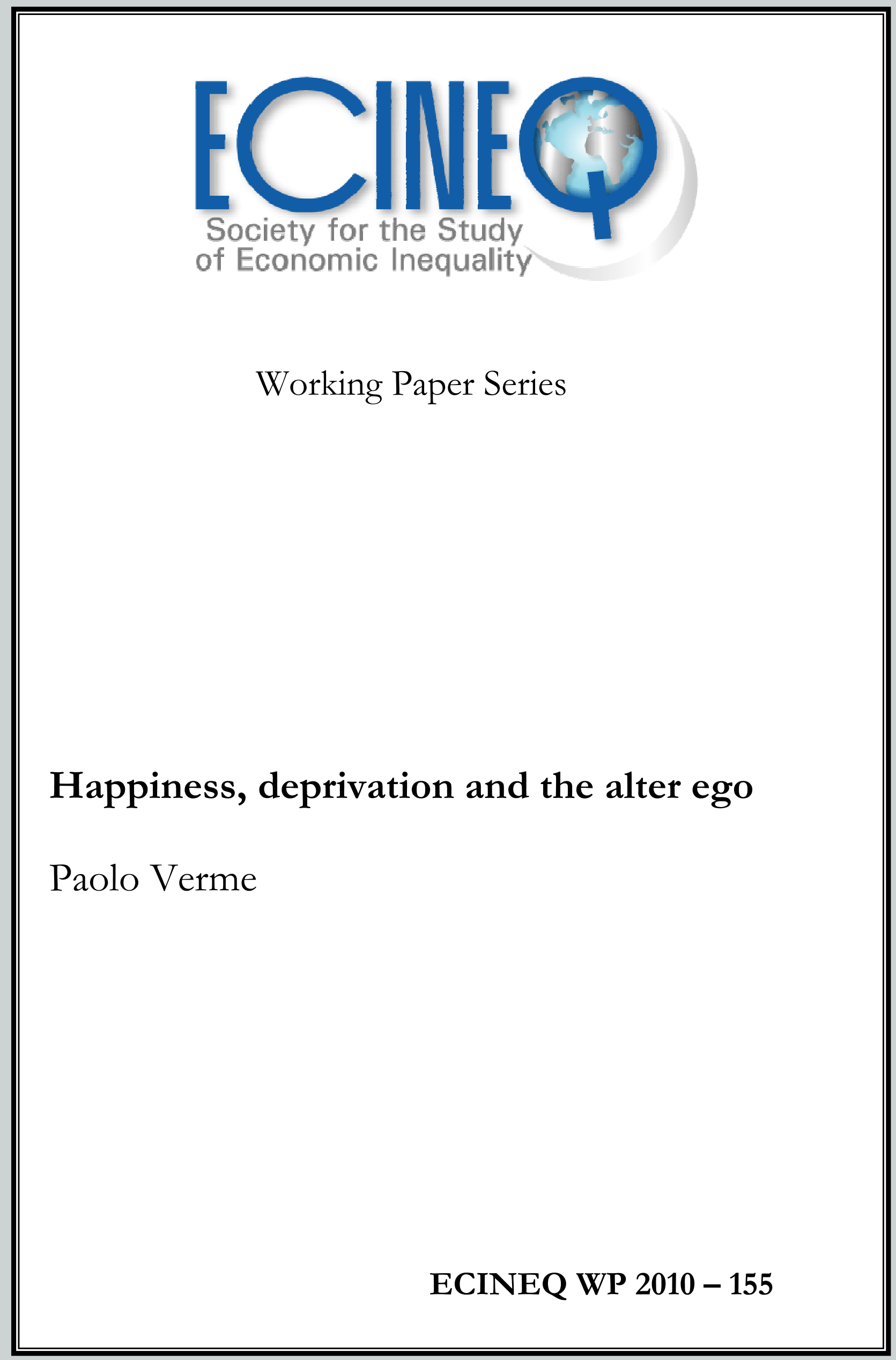




\title{
Happiness, deprivation and the alter ego*
}

\author{
Paolo Verme ${ }^{\dagger}$ \\ University of Torino
}

\begin{abstract}
The paper focuses on satisfaction with income and proposes a utility model built on two value systems, the 'Ego' system - described as one own income assessment relatively to one own past and future income - and the 'Alter' system - described as one own income assessment relatively to a reference group. We show how the union of these two value systems and the use of relative deprivation measures can lead to a model able to accommodate a wide range of theories on income and happiness. The model is then tested using the Consortium of Household Panels for European Socioeconomic Research (CHER), a collection of 19 panel surveys including over $1.2 \mathrm{~m}$. individual observations. We find absolute income to sit at the intersection between the 'Ego' and the 'Alter' systems and to play the most prominent role in explaining satisfaction with income. Relative deprivation is also found to be important for understanding the income-happiness nexus while we find income expectations to be less relevant once we control for absolute income. Overall, the 'Alter' system (the cross-section comparison with others) seems to be more relevant in valuing income than the 'Ego' system (the longitudinal self-comparison of income).
\end{abstract}

Keywords: happiness, deprivation, inequality.

JEL Classification: D6, I3, J3, O1.

\footnotetext{
* The present research was co-funded by the European Commission under the 6th Framework programmes Research Infrastructures Action (Trans-national Access contract RITA 0206040) hosted by IRISS-C/I at CEPS/INSTEAD, Differdange (Luxembourg).

† Address of correspondence: Department of Economics "Cognetti de Martiis", University of Torino, paolo.verme@,unito.it
} 


\section{Introduction}

In economics, utility is a measure of satisfaction and individuals are expected to maximize satisfaction by choosing the right consumption bundle under budget constraints and decreasing marginal returns. In such framework, an increase in income should lift the budget constraint and lead to increased utility.

Much of the happiness literature appeared over the past three decades has attempted instead to explain the 'Easterlin paradox'. Easterlin (1974) observed that average life satisfaction in the United States during the post-war period did not increase despite significant gains in GDP per capita, a finding that challenged the core economic axioms. Scholars across the social sciences have sought an explanation to the 'Easterlin paradox' and today there is a certain consensus on a number of stylized facts. First, income is important for happiness but has decreasing marginal returns both for countries and individuals. The fact that rich countries or individuals show a very weak or no relation between income and happiness is consistent with the fact that poorer countries and individuals show a positive association. Second, absolute income is only part of the story. Relative income, intended as income relative to the income of a reference group, is also important and progressively more important than absolute income as countries or individuals become richer. Rich countries and people are expected to be more sensitive to changes in relative income than to changes in absolute income. Third, aspirations and expectations about the future play an important role in determining present happiness and these expectations are formed in complex ways that may include past income, income of a reference group, income inequality, income growth and other factors.

This paper returns to the income-happiness relation consolidating into one 
framework old and new theories. We propose a model of happiness structured in two main value systems: the 'Ego' system described as the evaluation of one own income across time and the 'Alter' system described as the evaluation of one own income relatively to the income of others. We show how this distinction and the construction of a combined model can expand our understanding of happiness and how such model can accommodate the founding principles of many of the most prominent theories on income and happiness. We will focus on satisfaction with income rather than life satisfaction and use recent advances in the measurement of relative deprivation to structure a theoretical and an empirical model of income utility. In particular, we will draw on theories of relative deprivation and income inequality. The happiness literature has looked in detail at the question of relative income while has paid less attention to the questions of relative deprivation and income inequality. We will review some of the literature in these two areas and try to derive lessons for our model.

The model is then tested on a panel of rich countries where the Easterlin paradox is expected to be most evident. We use for this purpose one of the largest available collection of panel data, the Consortium of Household Panels for European Socio-economic Research (CHER), an harmonized data set that joins 19 panel surveys including over $1.2 \mathrm{~m}$. individual observations. Such data allow us to focus on a very restricted sample of individuals in prime working age and with regular working hours and use a continuous measure of individual income.

We find absolute income to sit at the intersection between the 'Ego' and the 'Alter' systems and to play the most prominent role in explaining satisfaction with income. Relative deprivation is also found to be very important for understanding the income-happiness nexus while we find income expectations to be of little 
relevance once we control for absolute income. Overall, the 'Alter' system (the cross-section comparison with others) seems to be more relevant in valuing income than the 'Ego' system (the comparison with oneself over time). These findings are robust to linearity tests and multiple specifications of the happiness equation, two issues that normally complicate the study of the relation between relative income and happiness.

The paper is organized as follows. In section 2 we discuss the role of relative deprivation and income inequality in theories of well-being. Section 3 outlines the theoretical model and section four describes the data and empirical specification. Section 5 presents results and section 6 concludes.

\section{Relative deprivation and income inequality in theories of well-being}

The idea that the evaluation of goods and people is not only related to absolute status but also to relative status is very old and can be traced in writings of ancient Greek philosophers, middle-ages theologists and seventeen and eighteen century social scientists. Adam Smith and Karl Marx shared this same view. In the Wealth of Nations Smith discusses at length the importance of a relative gain as compared to an absolute gain in at least two chapters, the chapter on colonies and trade (Chapter 9) and the chapter on rent of the land (Chapter 11). And Marx has been quoted to argue that "Our desires and pleasures spring from society; we measure them, therefore, by society and not by the objects which serve for their satisfaction. Because they are of a social nature, they are of a relative 
nature." 1 Some of the most prominent theories of the twentieth century consider explicitly the idea that relative status is essential to understand individual utility. This section discusses those theories that considered more in detail the question of relative deprivation and income inequality.

The three volumes of the 'The American Soldier' by Stouffer et al. (1949) are credited for introducing the concept of relative deprivation. The term is used to refer to the feeling of deprivation experienced by soldiers when comparing their status with the status of other soldiers in the same corps, in different corps or with civilians across different dimensions. The work clearly pointed to the importance of the reference group in making assessments about one own status and opened the way to a stream of contributions on relative deprivation in various sciences including sociology, political science, psychology and economics.

A first formalization of a model of relative deprivation can be found in Davis (1959). The author defines relative deprivation as the feeling accruing to a deprived person when status is compared with the status of a non-deprived. He distinguishes between within group comparisons and between group comparisons, reiterating the importance of the reference group. According to Davis, within group comparisons afffect the sense of 'fairness' experienced by individuals and can generate feelings of relative deprivation or relative gratification. Between group comparisons affect the sense of 'social distance' experienced by people leading to sentiments of 'relative subordination' or 'relative superiority'. We find here not only a formalization of the concept of reference group but also a distinction in the feelings that may emerge from within group and between group comparisons.

A second attempt to use formally the construct of relative deprivation can be found in Leibenstein (1962) theory of democracy. The author distinguished

\footnotetext{
${ }^{1}$ Quoted in Davies (1962)
} 
between three types of social comparisons: 1) 'Pure Pareto comparisons' in which each individual takes into account his own income and no one elses; (2) 'the share of the pie' comparisons in which each individual takes into account the income distribution from a relative point of view but not the absolute magnitude of his income; and 3) the 'compromise Pareto comparison' in which individuals take into account both the absolute magnitude of their income and their relative income position. Leibenstein provides a first attempt to combine the role of absolute and relative income in a utility model (the 'compromise Pareto comparison') and shows how, by combining these two perspectives, one can reach rather different conclusions for public policies from those suggested by the Pareto principles.

Perhaps the most popular theory of relative deprivation is found in Runciman (1966) theory of social justice. Runciman defines the situation of relative deprivation when an individual: 1) Does not have $X$; 2) Sees some other person or persons as having $X$; 3) Wants $X$ and 4 ) Sees it as feasible to have $X$. The first point defines deprivation as a lack of $X$ while the second introduces the concept of reference group, two aspects that we have already encountered with previous authors. The third and fourth conditions relate instead to wills and expectations. It is not sufficient to be materially deprived, it is also necessary to aim at a better status. Runciman brings to the fore the importance of the selection of the reference group and the role of expectations in shaping feelings providing in this way a value function of material well-being. "For the purpose of addressing relative deprivation, however, peoples estimates of their incomes are if anything more important than their actual income" (p. 189).

The concept of relative deprivation has also been widely used in theories of revolutions and social unrest. Gurr (1968) built a model of civil strife around the 
notion that relative deprivation is the basic precondition for civil strife. Relative deprivation is defined as "(...)peoples perception of the discrepancy between value expectations (goods and material conditions that individuals think they are entitled to) and their values capabilities (the amounts of goods and conditions that individuals think they can get and keep)." (p. 1104). Here the emphasis is on the gap between possessions and expectations irrespective of the amount of possessions and of the legitimacy of expectations. While Runciman opens the chapter on expectations and relative deprivation, Gurr offers an alternative explanation on how expectations lead to deprivation by focussing on the gap between actual and expected entitlements.

The role of expectations is also important in theories that emphasized income mobility rather than income relativity. Over a century ago Karapetoff (1903) wrote: "The degree of life-satisfaction of separate individuals or of whole societies is measured, not by the absolute quantity of goods possessed, but by the rapidity with which this quantity is increasing." (p. 681). Karapetoff represented this concept with what he called the 'progress curve', a growth curve with an initial slow path of growth followed by rapid growth and maturity. He argued that happiness is maximized when the progress curve reaches its maximum steep rather than its maximum level. "The individual at this period is sanguine and full of hope: every day brings something new to his life; he is conscious of the fruit of his labor." A similar idea is found in Davies (1962) theory of revolutions. For Davies, revolutions are most likely to occur during recessions that follow periods of growth rather than during periods of persistent poverty. And people are the happiest during periods of sustained growth rather than during periods of high but stable wealth, a phenomenon that the author illustrates graphically with a $J$ - 
shaped curve. Both Karapetoff and Davies emphasize the role of change in raising or crushing expecations. In these theories, it is change that shapes deprivation and the notion of 'relative' refers to one own past or expected future situation rather than to the comparison of one own status with that of a reference group.

Income mobility and the role of expectations are also central to Hirschman and Rothschild (1973) tunnel effect theory. ${ }^{2}$ "The tunnel effect operates because advances of others supply information about a more benign external environment; receipt of this information produces gratification; and this gratification overcomes, or at least suspends, envy." (p. 546) "In this eventuality, the increase in income inequality would not only be politically tolerable; it would also be outright desirable from the point of view of social welfare." (p. 548). The tunnel effect theory provides a first insight into the relation between deprivation and inequality and predicts that income inequality may increase rather than reduce feelings of satisfaction, at least in the short-term. In the long-term, the persistence of immobility in the face of mobility of other members of society can turn into an explosive social device. Envy can quickly replace gratification and reverse the tunnel effect. This is strikingly similar to Davies (1962) J-curve hypothesis although, as noted by Hirschman, in the $J$-curve hypothesis a downturn is a necessary condition for upheaval whereas in the tunnel effect hypothesis a downturn is not necessary for reversing the tunnel effect. It is sufficient that the people who observe mobility and who are not moving remain stuck in such condition for a sufficiently long period of time. The tunnel effect theory provides in this way different predictions on how a rise in income inequality turns into feelings of deprivation in the short and

\footnotetext{
${ }^{2}$ The seminal paper is usually quoted as Hirschman (1973) but the article contained a mathematical appendix written by Rothschild that clarifies and expands the tunnel effect concept to the long-term case, when the tunnel effect is reversed. This important addition to the theory is often neglected when the tunnel effect theory is quoted but is an essential part to understand the short-term nature of the tunnel effect.
} 
long-term.

An alternative formalization of the relation between relative deprivation and income inequality can be found in Yitzhaki (1979). Yitzhaki proposed to measure the concept of individual relative deprivation described by Runciman (1966) by summing up the distances between one own income and all other incomes larger than one own's. The sum of these individual scores across the population can then be interpreted as a relative deprivation measure for a society. Yitzhaki showed that the relative deprivation index constructed in this way is in fact equal to the absolute Gini index (the Gini multiplied by the mean), a finding that generated a stream of contributions exploring further the properties and use of such index (Hey and Lambert (1980); Berrebi and Silber (1985); Chakravarty et al. (1995)).

In this tradition, the reference group is composed of richer people by construction, deprivation is understood in terms of material deprivation and 'relative' is intended as income differences between one own income and the group of richer people. As compared to previous contributions, this literature paid less attention to the notion of feelings of deprivation (equating feelings of deprivation to material deprivation) $)^{3}$ and to the notion of selection of the reference group (equating richer people to the reference group). ${ }^{4}$ In a sense, while the pre-Yitzhaki literature

\footnotetext{
${ }^{3}$ Hirschman and Rothschild (1973) argued that (...) "the predominant meaning of the term relative deprivation refers to the feelings expressed by a person or group of persons who are falling behind others or who see others catching up with them in regard to income, influence, and status." (p. 546) and the psychologist Crosby (1979) specified that: "First, the term "relative deprivation" is used to refer to the emotion of deprivation, an emotion generally conceived of as one type of anger roughly synonymous with a feeling of resentment or dissatisfaction or with a sense of grievance".

${ }^{4}$ It should be noted that in a further paper Yitzhaki (1982) discusses the question of reference groups which is obviously not alien to the author. Here we focus on the relative deprivation measure that became most popular in economics following the seminal 1979 article. A further confusion originates from the use of the terms 'absolute' and 'relative' in statistical measurements. In his seminal book on income inequality Gini (1912), spoke of the relative mean difference of incomes as the absolute mean difference divided by mean income and defined his measure of income inequality as equal to half of the relative mean difference. The Yitzhaki relative
} 
focussed on feelings of deprivation and reference groups but did not provide an empirical tool to measure relative deprivation defined in these terms, the postYitzhaki literature provided a tool to measure relative deprivation but lost some of the core elements that defined relative deprivation in the first place.

An attempt to generalize the Yitzhaki approach while introducing a mechanism for the selection of the reference group is provided by Panning (1983). The author builds a model of income inequality and relative deprivation exploiting earlier postulates by Festinger (1954) and Nagel (1974) whereby a) The more unequal the assets of two individuals, the less happy the poorer will feel if he compares himself with the richer and 2) The tendency of two individuals to compare their own wealth with that of the other varies inversely with the difference in their wealth. Here we find the same idea found in Yitzhaki that relative deprivation increases with inequality and that feelings of deprivation arise from income inequality but also the additional insight that the value given to income differences is inversely proportional to such distance. This last proposition can be regarded as a mechanism to select the reference group.

More recently, Clark and Oswald (1996) have looked into the possibility of selecting the reference group according to individual characteristics on the assumption that individuals compare themselves first and foremost with their likes. In such framework, incomes predicted on the basis of individual characteristics provide a simple mechanism for the selection of the reference group and predicted incomes become an alternative tool to study satisfaction. Other contributions have looked more in detail at how to include such selection mechanism of the reference group into measures of relative deprivation constructed on income (Verme and

deprivation index is equal instead to the absolute Gini index (half of the absolute mean difference) which complicates further the interpretation of the term 'relative'. 
Izem (2008) and Silber and Verme (2009)) or on labor indicators (Verme (2009)). In these measures, the selection of the reference group is reflected in predicted incomes and the predicted income distribution is considered jointly with the income distribution combining in this way the notions of income, reference group, income rank and income inequality into one measure.

Happiness research has also greatly emphasized the role of the reference group and relative income in explaining life satisfaction. Clark et al. (2008) provide a very comprehensive review of theoretical and empirical contributions to the explanation of the Easterlin paradox based on absolute and relative income measures. They recognize the importance of social comparisons and adaptation when considering income in a happiness function and the existence of internal and external reference points for income comparisons, the first described as past incomes and the second described as income of a reference group. Put it simply, most of the happiness models described in the review consider the following utility function:

$$
U_{i, t}=U\left(u_{1}\left(Y_{i, t}\right), u_{2}\left(Y_{i, t} / Y_{t}^{*}\right)\right)
$$

where: $i=$ individual; $t=$ present time; $Y=$ income; $Y^{*}=$ Relative income (where relative income can be interpreted as one own past income or average income of the reference group).

In the equation above, the internal and external reference points are captured by the second term on the right-hand side where one own income is put in relation with one own income in the past or the income of a reference group. These types of models are popular in happiness research and they have been able to explain rather well the Easterlin paradox, contributing to define those stylized facts on income and happiness that we have outlined at the outset of this paper. 
Yet, this literature has not considered in great detail relative deprivation intended as perceived deprivation, rarely discusses the mechanism for the selection of the reference group, does not attribute great importance to income inequality and does not approach the question of the relation between relative deprivation and inequality. These are aspects that the relative deprivation and income inequality literature reviewed in this section have addressed. In the next section, we propose a model that builds on this recent happiness literature and includes some of the critical issues emerged from the discussion on relative deprivation and income inequality theories.

\section{Model}

We can think of the value system of an individual as composed of two sub-value systems which we will call the 'Ego' system and the 'Alter' system. ${ }^{5}$ We will refer to the 'Ego' system when individuals evaluate their own income by comparing it with their own income in the past or with their future expected income. The 'Ego' system is longitudinal in nature and panel data are necessary to evaluate such system. We will refer to the 'Alter' system when individuals evaluate their own income relatively to the income of others and we will refer to 'others' as the reference group. We will consider this system cross-section as it is standard in the happiness literature, although it is potentially possible to consider incomes of the reference group in the past or in the future. ${ }^{6}$

Visually, the two value systems model that we propose can be depicted as in

\footnotetext{
${ }^{5}$ This terminology was also used by Davis (1959).

${ }^{6}$ We will not consider this last option as there is no particular economic reason to introduce the temporal notion of reference group (there is no reason to argue that people compare their own income today relatively to an income distribution in the past) while such addition would greatly complicate the model.
} 
Figure 1: A Value Model of Happiness and Income

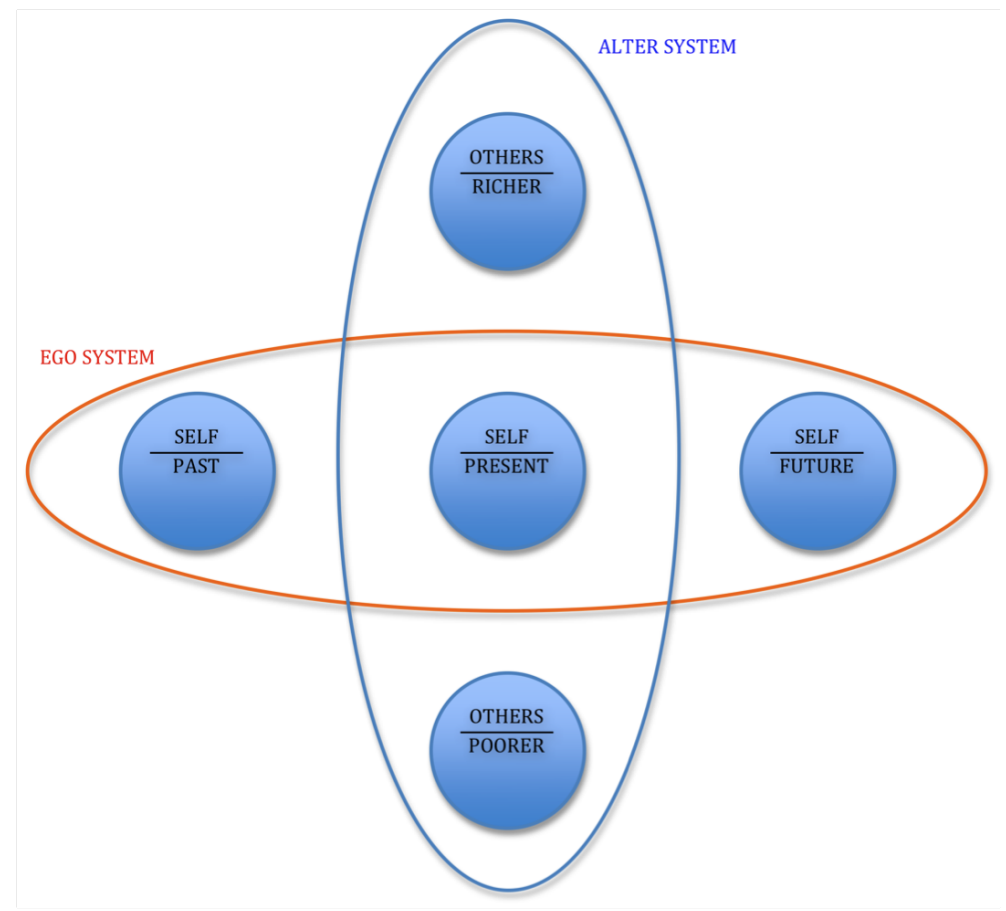

Figure 1. In the Figure, the 'Ego' system is shown horizontally, from the past to the future as we move from left to right. The 'Alter' system is instead shown vertically. On the top side we find richer people and on the bottom side we find poorer people. The two systems cross at the income of person $i$ at time $t$, the individual at the present time.

The two value systems contribute to shape the individual utility function. In its most simplistic form, an income utility function that describes the model should therefore have the following two components:

$$
U_{i, t}=U\left(u^{e}\left(Y_{i, T}\right), u^{a}\left(Y_{t}^{*}\right)\right)
$$

where: $U_{i, t}=$ Individual utility at the present time; $Y_{i, T}=$ Individual income 
through time with $T=(t-1, t, t+1)^{7} ; Y_{t}^{*}=$ Income of a reference group at the present time; $u^{e}()=$. Evaluation function of the 'Ego' system and $u^{a}()=$. Evaluation function of the 'Alter' system.

Before we introduce the model more in more detail, a few clarifications are necessary. First, we will not make a distinction between utility and happiness. This is a point that is not often discussed in the happiness literature and that deserves attention. However, the practice in the happiness literature has been to use the two terms as synonymous (Easterlin (2001) and Alesina et al. (2004)) and this is what we do in this paper.

Second, most studies on happiness and income consider happiness either with direct questions on happiness or with questions on life satisfaction. In this paper, we focus instead on the notion of satisfaction with income. Life satisfaction is evidently the product of a multitude of factors and income satisfaction can be considered as a sub-component of life satisfaction together with satisfaction with family and friends, satisfaction with housing and others. Presumably, variables such as income, relative income and income inequality affect life satisfaction through satisfaction with income. By focussing on income satisfaction, we expect to reduce noise in understanding how income affects life satisfaction.

Third, unlike most happiness studies, we consider both individual income measured from household surveys and GDP per capita. Cross-country studies often consider GDP per capita as a measure of income while panel studies on individual countries rely on household income data. These two traditions emerged because cross-country studies such as the World Values Surveys or the US Social Survey do not contain information on individual income ${ }^{8}$ whereas, in longitudinal studies

\footnotetext{
${ }^{7}$ For simplicity, we model the past as $t-1$ and the future as $t+1$.

${ }^{8}$ Except for variables such as income scales where respondents are asked to what income group they belong to.
} 
on single countries such as the British or German panels, GDP per capita cannot be used as explanatory variable in an happiness equation. Although we should expect GDP per capita and average household income to follow a similar pattern over time, these are structurally different measures and can follow very different paths, especially in the short-term. ${ }^{9}$ It is therefore possible that cross-country and longitudinal studies reach different conclusions because of the use of different measures of income. The Easterlin paradox was constructed on GDP data while several contributions in the empirical literature have focussed on household income in an effort to explain the Easterlin paradox. In this paper, we will employ both variables.

\subsection{The 'Ego' system}

This section models more in detail the first component of the utility function proposed. We explained that the 'Ego' system refers to the evaluation of one own past, present and future income. Thus, the 'Ego' sub-utility function is described as

$$
U_{i, t}^{E}=U\left(Y_{i, t-1}, Y_{i, t}, Y_{i, t+1}\right)
$$

where $U^{E}$ is income utility in the 'Ego' value system, $i$ refers to individuals, $t$ refers to present time and $t-1$ and $t+1$ refer respectively to past and future incomes.

Empirically speaking, the measurement of present income requires cross-section data on income which are commonly available in surveys on income and wealth

\footnotetext{
${ }^{9}$ During the early years of the new millennium, Kazakhstan was growing at an average of $9 \%$ per year in terms of GDP per capita while household income was growing at only $0.7 \%$ on average (Verme (2010)).
} 
worldwide. The measurement of past incomes requires instead panel data where the same individual can be followed over time. These surveys are more difficult to find and only a few tens of countries dispose of such instrument, which makes the cross-country study of income dynamics difficult. However, this is a problem that we can overcome by using the CHER data set described further in the paper.

More problematic is the empirical specification of future expected income. If surveys contain questions on expected future income this is a simple and effective solution to the problem. People are asked about their expected future income and this variable is included into the empirical model. If, instead, this information is missing we need to construct some theoretical model on how people construct expectations about future incomes. In this case, expected future income is a latent variable and some assumptions are necessary to construct a proxy for such variable. Here we can seek help from the theoretical review provided earlier in the paper and argue that people use information about their own income mobility, the mobility of others in the reference group and the more general development with the economic situation in the country. This is information that individuals are most likely to have and that we should expect contributing to future income expectations. We should therefore expect future income to be a function of one own income growth, income growth of the reference group and growth of GDP per capita as follows: ${ }^{10}$

$$
E Y_{i, t}=E\left(Y_{i, t+1}\right)=f\left(\Delta Y_{i, t}, \Delta Y_{t}^{*}, \Delta G D P / \operatorname{cap}_{t}\right)
$$

where $\Delta$ refers to the growth rate and $t$ refers to the post-growth period. These

\footnotetext{
${ }^{10}$ Note that $E\left(Y_{i, t+1}\right)$ represents both the perceived and statistical notions of expected income. It is what people think their future income will be and the expected value of a distribution of possible expected incomes centered on the mean. We put $E Y_{t}=E\left(Y_{i, t+1}\right)$ to underline that expectations about future income are formed at the present time and contribute to present utility.
} 
are the 'dynamic' ingredients of the income utility function as suggested by the literature we have reviewed. However, the literature is rather vague in indicating how the value function $f($.$) is shaped. To address this issue, we simply assume that$ expected income is equal to present income inflated by the average growth rate of income, reference income and GDP per capita so that expected future income amounts to a simple formula as follows:

$$
E Y_{i, t}=Y_{i, t}\left(1+\left(\left(\left(\Delta Y_{i, t}+\Delta Y_{t}^{*}+\Delta G D P / \operatorname{cap}_{t}\right) / 3\right)\right)\right.
$$

The formula implicitly assumes that the three measures are weighted equally. Other assumptions that attribute different weights to the different components may also be used. For example, we may argue that individual income growth should weigh more for future expectations than other people's income growth. However, the relative deprivation literature reviewed has pointed to the importance of relative income in shaping expectations while much of the literature on income mobility and on happiness has highlighted the role of GDP growth. Moreover, we should expect the weight attributed to the different components to vary considerably across individuals. Thus, the average growth across the three components can be regarded as a reasonable assumption.

We may also assume that past income contributes to present satisfaction with income only through expected future income. There is no particular reason to assume that last year's income contributes to this year's satisfaction with income unless savings are involved. On the contrary, it is reasonable to assume that past and present incomes contribute to shape future expectations and that these expectations may change the way we feel about present income. Considering also that income growth is constructed with past and present income $\left[\Delta Y_{i, t}=\left(Y_{t}-\right.\right.$ 
$\left.\left.Y_{t-1}\right) / Y_{t-1}\right]$, the 'Ego' income utility function can be reduced to

$$
U_{i, t}^{E}=U\left(Y_{i, t}, E Y_{i, t}\right)
$$

\subsection{The 'Alter' system}

We defined the 'Alter' system as the evaluation of one own income relative to the income of others in a reference group. Therefore, the sub-utility function of the 'Alter' system should include individual income, the income of reference individuals and the cardinal and ordinal sequences of all incomes, i.e. distances between incomes and income rank. A utility function that captures these elements may look as follows:

$$
U_{i, t}^{A}=U\left(Y_{i, t}, Y_{t}^{*}, r_{t}\right)
$$

where $t$ is the present time, $Y_{t}^{*}$ is the income of the reference group and $r$ is an indicator of rank.

The key issue to define in the 'Alter' system is the reference group. How do people select the reference group? Our hypothesis is that individuals compare themselves with their likes, people with similar individual characteristics such as age an education as already described for Clark and Oswald (1996) and Verme and Izem (2008). Here we borrow from a more recent paper by Silber and Verme (2009) that proposes a measure of relative deprivation including the notions of reference group, absolute income, relative income and income rank into one index. The index contains all the ingredients of the 'Alter' utility function proposed and has the advantage of structuring the relation between these ingredients into a formula. One of the problems experienced by the empirical literature on happiness 
and income is that variables such as absolute income, relative income and income inequality are highly correlated and regression coefficients and significance levels can be affected by such collinearity. Reducing these variables into a structured index overcomes the problem. The Silber-Verme index is defined as follows:

$$
R D=[\ldots 1 / n \ldots]^{\prime} G\left[\ldots s_{i} \ldots\right]-[\ldots 1 / n \ldots]^{\prime} G\left[\ldots w_{i} \ldots\right]
$$

where: $[\ldots 1 / n \ldots]^{\prime}$ is the row vector of population weights; $G=$ is the 'G' matrix as defined in Silber (1994) (a square matrix with all '0' along the diagonal, all '1' above the diagonal and all ' -1 ' below the diagonal); $\left[\ldots s_{i} \ldots\right]$ is the column vector of shares of income sorted in descending order of incomes and $\left[\ldots w_{i} \ldots\right]$ is the column vector of shares of predicted incomes sorted in descending order of incomes.

The first component on the right-hand side of the equation is the Gini coefficient of incomes (GY). The second component (GW) is a scalar calculated with matrix calculus in the same fashion as the Gini of incomes but based on predicted income shares sorted in order of incomes. Predicted incomes are estimated with a linear equation where the explanatory variables are variables thought to be used by the population to select the reference group.

Econometrically, predicted incomes are closer for people who have similar characteristics. In other words, more weight is given to the likes of people, a principle that complies to the notion of reference group we have adopted. Economically, predicted incomes can be interpreted as the income expected by individuals given their own characteristics as compared to the characteristics of others in the reference population. In this way, both the notions of selection of the reference group and creation of expectations based on this selection are captured.

In substance, the relative deprivation index proposed captures incomes, pre- 
dicted incomes, rank in incomes, the reference group and income inequality, all the notions we wish to have in the 'Alter' model. Note that the $R D$ relative deprivation measure, unlike the Gini coefficient, can be estimated and is meaningful at the individual level. This is interpreted as the individual score of relative deprivation $(R D I)$, adds up to relative deprivation for a society and it is decomposable by population sub-groups. ${ }^{11}$ The adoption of the RDI index reduces the specification of utility in the 'Alter' system to

$$
U_{i, t}^{A}=U\left(R D I_{i, t}\right)
$$

and completes the composition of the aggregated income utility of the 'Ego' and 'Alter' systems as follows:

$$
U_{i, t}=U\left(Y_{i, t}, E Y_{i, t}, R D I_{i, t}, Z_{i, t}\right)
$$

where $U_{i, t}$ is satisfaction with income and $Z_{i, t}$ is a vector of variables controlling for other non-income factors affecting satisfaction with income.

\section{Data and empirical specification}

The database we use is the Consortium of Household Panels for European Socioeconomic Research (CHER). ${ }^{12}$ This is a collection of panel survey data whose variables have been harmonized into a consistent data set. It includes 19 panel

\footnotetext{
${ }^{11}$ The proposed index is also decomposable into two components representing structural mobility (change in income) and exchange mobility (change in rank). For more details see Silber and Verme (2009).

${ }^{12}$ The consortium was established in 2000 and is coordinated by CEPS/INSTEAD in Luxembourg who also holds the rights for the use of the data. The paper was written by the author during a visiting period at CEPS/INTEAD financed by the European Commission's IRISS program. For more information on the CHER project see Schmaus et al. (2003).
} 
studies carried out between 1990 and 2001 and totaling over 1.2 millions individual observations, which makes it the richest data archive of its kind. The data set contains a wealth of variables including among others income, individual characteristics and satisfaction with income. It is therefore a unique resource to combine individual variables such as individual income with group variables such as GDP per capita and income inequality and reconsider the income-happiness relation within the extended model proposed.

The sample we consider includes individuals in age 30-50 with a declared working time of at least 15 hours per week and with positive incomes. This excludes most individuals in precarious working conditions and in the process of entering or exiting the labor market. We opted to look at individuals with stable working conditions so as to reduce the impact on satisfaction with income of non income factors related to work such as youth contracts or pre-retirement arrangements.

Data are pulled into a single cross-country equation with country and year fixed effects. The dependent variable is satisfaction with income and is measured on a five steps ladder where ' 1 ' stands for "Not at all satisfied" and '5' stands for "Completely satisfied". Estimations are made with an ordered logit model and robust standard errors. The theoretical description of the model provides enough structure for the empirical specification. The model requires current income $(Y)$, expected income $(E Y)$ and relative deprivation $(R D I)$ as well as a vector of control variables as follows:

$$
\begin{aligned}
& S_{i, t}=\alpha+\beta_{1}\left(\ln \left(Y_{i, t}\right)\right)+\beta_{2}\left(\ln \left(E Y_{i, t}\right)\right)+\beta_{3}\left(\ln \left(R D I_{i, t}\right)\right) \\
& +\gamma_{1}\left(X_{i, t}\right)+\gamma_{2}\left(C_{c}\right)+\gamma_{3}\left(T_{t}\right)+\eta_{i, t}
\end{aligned}
$$

where $S$ is satisfaction with income, $X$ is a vector of control variables for individual characteristics, $C$ is a vector of country dummies, $T$ is a vector of 
years dummies and $\eta$ is the error term ( $c$ and $t$ stand for countries and years respectively). $\beta$ stands for the coefficients of our variables of interest and $\gamma$ stands for the coefficients of the control variables. This is therefore a static cross-section model where the dynamic growth considerations are structured into the equation through expected income.

As a measure of income we use annual individual income net of taxes. Annual income was preferred to shorter measures to avoid problems of seasonal income fluctuations while net income was preferred to gross income as individuals presumably care about take-home pay rather than pre-tax income. Given the cross-country nature of the equation, this variable has been transformed in constant terms with base 2000, in dollar equivalent and in Purchasing Power Parity (PPP). For the transformation in real terms we used the CPI index published by the IMF for each year and each country. ${ }^{13}$ For the US dollar equivalent PPP transformation we use a conversion factor prepared by the CHER consortium. ${ }^{14}$ In equation [11], the income variable has been further transformed in natural logarithm but alternative transformations will also be considered.

Expected income $(E Y)$ was calculated inflating current income by the average growth rate of individual income, reference income and GDP per capita as indicated in the previous section. GDP per capita was also used in dollar equivalent and purchasing power parity as provided by the IMF for each year and each country. By construction, expected income is correlated with income which may or may not create problems for the estimations. This is an issue that is further discussed in the results section.

Relative deprivation (RDI) was calculated at the individual level following the

\footnotetext{
${ }^{13}$ See http://www.imf.org/external/data.

${ }^{14}$ This variable was kindly provided by Gunther Schmaus at CEPS/INSTEAD, Luxembourg.
} 
Silber-Verme formulation as described in the model section. By construction, relative deprivation for individuals (RDI) sums up to relative deprivation for the population (RD). Recall that RDI uses incomes and predicted incomes. The variables included into the equation for predicting income are gender (a dummy for females), age (in years and in squared form), education levels (primary, secondary and tertiary education), a dummy for the self-employed as opposed to the employees and a dummy for state sector employment. These are the variables we thought relevant for the selection of the reference group. Note that RDI was further scaled up to allow for various non linear transformations of the variable.

As individual controls in the happiness equation $(X)$ we use gender (a dummy for females), age (in years and in squared form), education levels (primary, secondary and tertiary education), marital status (dummy for formally married people), household size (in units), a dummy for the self-employed versus the employees and a dummy for state sector employment.

\section{Results}

Modeling empirically the equation proposed presents some relevant challenges, some of which have been addressed in the construction of the model. A pooled cross-country equation over multiple years is affected by country heterogeneity and time effects, two issues that were addressed by inserting country and fixed effects. The study of satisfaction with income restricts the sample to working individuals but working histories and status vary greatly across workers. To reduce this problem, we restricted the sample to people in age between 30 and 50 years old, eliminating in this way most of those people who are in the process of entering or exiting the labour market. We also restricted the sample to those with at 
least 15 hours of work per week so as to limit the noise that would accrue from individuals with very irregular or scarce working hours. The estimation of expected income also required the use of growth rates for income, reference income and GDP per capita. The use of these variables to construct expected income reduces the usable sample to panel observations. Working cross-country with several currencies implied that we had to transform all incomes into constant values, per dollar equivalent and in purchasing power parity. We also make use of several variables to control for various individual characteristics and this further reduced sample size for the regressions. The factors above combined reduced our usable sample to about 193,000 observations. These are some of the reasons that explain why it is so difficult to model the relation between income and happiness including most factors suggested by the literature and justifies the use of the CHER database for such purpose.

Non-linearity and multicollinearity are two additional issues to consider. As suggested by the theoretical and empirical literature on income and happiness, the relation between these variables may be non-linear. To address this issue we opted to transform the three variables of interest (income, expected income and relative deprivation) into logarithmic, exponential and categorical form and compare regression coefficients across these different types of transformations. This is important not only to uncover non linear traits but also to explore covariance within quantiles.

Multicollinearity is a further issue often neglected by the happiness literature. This literature has made great use of a range of income related variables including income, relative or reference income constructed in various ways, lagged income, income inequality, income deprivation and others. All these variables are built 
starting from the same indicator of income and are correlated with income by construction. Statistical packages drop automatically variables if there is perfect collinearity among regressors but not if collinearity is below perfect.

Multicollinearity does not affect the overall prediction of the model but affects coefficients of individual predictors and generally increases standard errors making predictions more difficult to detect. The solutions to the problem are to drop one of the variables, group variables into one indicator and/or use a very large sample to increase the probability of significance. The first two solutions defeat the purpose of these types of models which seek to explain satisfaction with variables such as income and relative income in conjunction, while the third solution is hard to adopt when one works with only one country. In this paper, some of the explanatory factors described have been grouped into the expected income and relative deprivation variables and we also dispose of the largest data set available for this type of studies. In addition, we will test all possible specifications of the equation with the three variables of interest.

Tables 1 and 2 present the results. Table 1 includes equations for the linearity tests and table 2 includes equations for the collinearity tests. Predictors for individual characteristics are shown only in Table 2 while the results for country and year fixed effects are omitted from both tables for the sake of clarity. ${ }^{15}$ The tables report odds ratios and z-statistics.

Note that Table 1 reports results for the same four equations (column headings 1, 2, 3 and 4) by variable of interest (income, expected income and relative deprivation). Equation 1 uses the three variables in simple form, equation 2 in logarithmic form, equation 3 in simple, squared and cubic form and equation 4 in quantile form. In all four equations of Table 1, the three variables of interest are

\footnotetext{
${ }^{15}$ These results are available form the author on request.
} 
used together whereas Table 2 considers alternative combinations of variables in turn.

Absolute income shows a consistent positive and significant sign in all equations in Table 1 (columns 1-4) and 2 (columns 1, 2 and 4). ${ }^{16}$ The odds of belonging to the highest income satisfaction level are higher if income is higher and the odds ratios for the variable in logarithmic form are rather high, between 0.5 and 1 . The relation is also clearly linear in income satisfaction. Whether the variable is used in simple, logarithmic, squared, cubic or categorical form, the coefficient is always positive and significant. It is also noticeable that when the variable is split into classes the odds ratios increase in a rather linear way moving from the lowest to the upper class. This variable is also not affected by model specification. Whether we include or exclude expected income or relative deprivation the coefficient is consistently positive and significant.

We shall conclude that absolute income invariably increases satisfaction with income. This result was expected and complies with most theoretical and empirical contributions. It is also not necessarily in contrast with the 'Easterlin paradox'. The paradox was originally based on the relation between average satisfaction with life and GDP per capita over time in the US. Here we consider instead individual satisfaction with income and individual income cross-country. Much of the literature on the 'Easterlin paradox' has used GDP per capita or individual income depending on data availability without really making a normative distinction between the two measures. We argue instead that these are two very different variables and cannot be used as substitutes to study the 'Easterlin paradox'. In our model, GDP per capita is important but enters the individual utility function

\footnotetext{
${ }^{16}$ Note that in Table 1 , coefficients for the three variables of interest are reported next to each other but they belong to the same four equations.
} 
through expected income.

Expected income is a more volatile variable and the interpretation of the results leads to some important caveats. The variable is highly correlated with income (Pearson correlation coefficient $=+0.96)$. When the variable is used in conjunction with income, it shows a negative sign (Table 1, column 1 and 2 and Table 2, column 1) whereas it shows a positive sign when used without income (Table 2 , columns 3 and 5 ). The variable would be positively correlated with income satisfaction but once income is taken into account the residual effect is negative. This effect is not uncommon with highly collinear variables. For example, two variables $x$ and $y$ positively correlated with a third variable $z$ and with the same mean and variance but different Kurtosis and Skewness can show opposite signs when regressed against $z$. This is what we observe with expected income and is a phenomenon that may well apply to other income measures such as relative income or income inequality. It is important therefore to rely on an economic framework that justifies the use of the variables separately or in conjunction. In our model, income and expected income are part of the same value system and should be used in conjunction.

Expected income also shows a non-linear relation with income satisfaction (Table 1, columns 3 and 4). When expected income is squared or cubic, the sign turns positive and is still (weakly) significant (Table 1, column 3). Instead, when the variable is categorized, the relation with income satisfaction is positive and significant for the second decile and non significant for the other deciles (Table 1, column 4). These last two results are not in contrast. What we observe is that the slope of the relation with income satisfaction is first negative and significant for very low levels of expected incomes and then turns positive and weakly significant 
for higher levels whereas within the smaller decile samples the significance of the relation is lost.

Non linearity of expected income can be better appreciated looking at Figure 2. In Figure 2 we plotted income satisfaction (conditional on the control variables) and expected income by quantiles of expected income (conditional on income, relative deprivation and control variables). The first and last deciles show a negative relation whereas the central quantiles show positive or flat relations. This is consistent with results in Table 1, column 4 where the base category is the first decile. Here we see that the relation turns positive and significant for the second decile and non significant for upper deciles.

In substance, the relation between income satisfaction and expected income conditional on income is complex to detect, non linear and also weak, with rather low odds ratios. Of course, this may be explained by the particular construction of the expected income variable that we proposed but such construction is not economically unsound and any other alternative measure of expected income would be structurally correlated with income and likely to exhibit similar problems.

Relative deprivation shows instead a rather consistent negative relation with income satisfaction. In both tables 1 and 2, the signs are always negative and significant with the exception of the squared and cubic values of the variable that are non significant (Table 1, column 3). For this variable, the within deciles coefficients are all negative and significant and the odds ratio increase in value linearly (with one exception) as we move from low levels of relative deprivation to higher levels. Relative deprivation has always a negative effect on satisfaction with income irrespective of the decile considered. The variable is correlated with both income and expected income (Pearson correlation coefficients of about +0.6 for 
both variables) and removing the other two variables increases significantly the odds ratios (Table 2, columns 2, 3 and 6). These results are consistent with the theoretical and empirical literature that point to relative deprivation as an important factor in explaining satisfaction and reinforce the findings that the position of individuals within a reference group is important in explaining satisfaction.

Signs and significance of individual characteristics are largely as expected and consistent with previous literature (Table 2). Females have greater income satisfaction than males. This result is significant and negative only in column 6 of Table 2 where absolute and expected incomes are omitted. Thus, income being equal, women are more satisfied with income. ${ }^{17}$ Age has the expected negative sign for young age while it turns positive for older ages. This is true whether absolute and/or expected incomes are included into the equation. Education increases the odds of high income satisfaction as expected. Secondary and tertiary education progressively increase the odds of having higher satisfaction as compared to primary education. Marriage also increases satisfaction with income whereas the number of children decreases it. Both these findings are well known in the happiness literature. To be self-employed significantly increases the odds of being happier with income as compared to the to the status of employee while state and private sector workers do not show any significant difference.

\footnotetext{
${ }^{17}$ Note that is not in contrast with the recurrent finding of wage discrimination against women given that the positive sign emerges only when we control for income.
} 


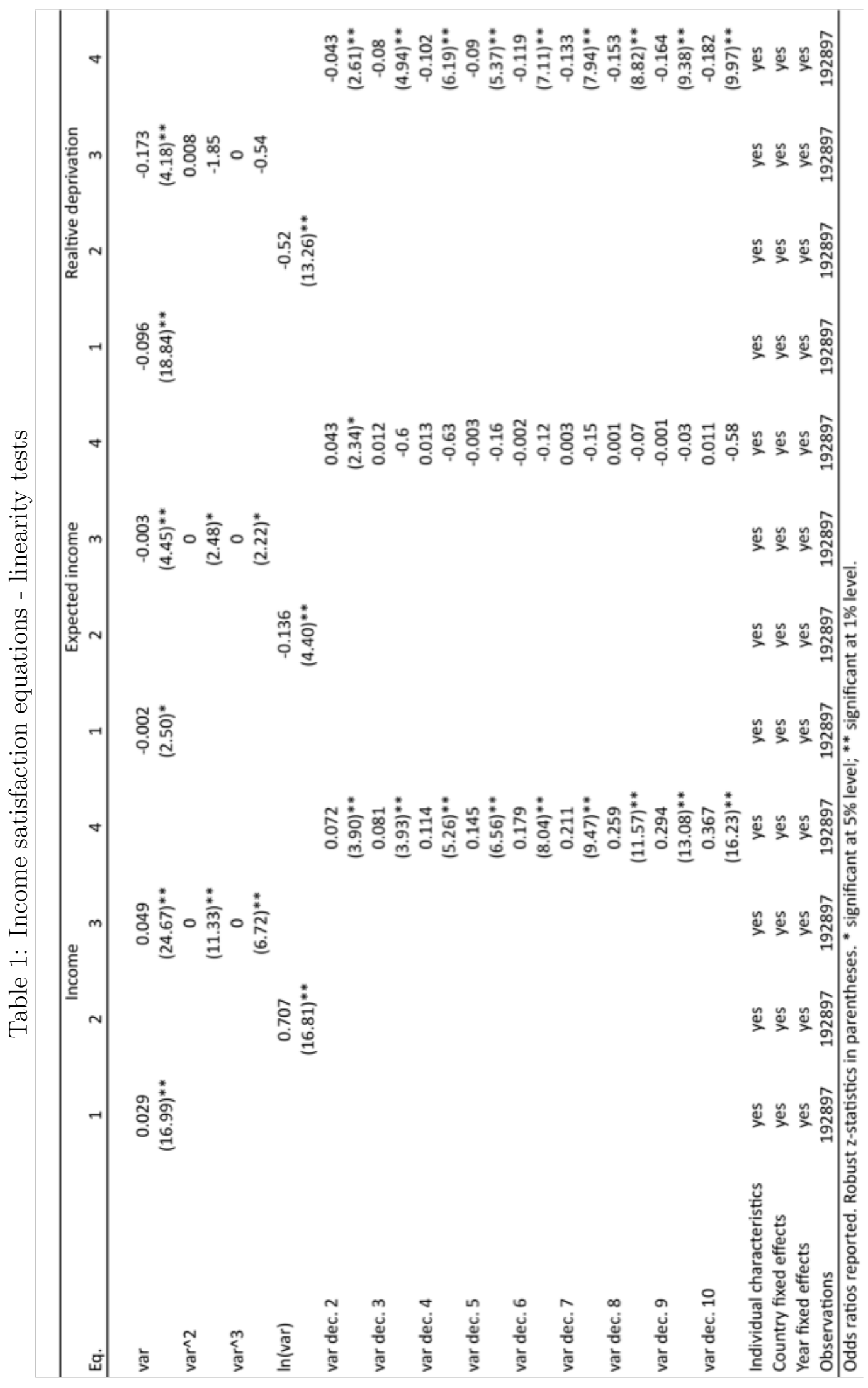




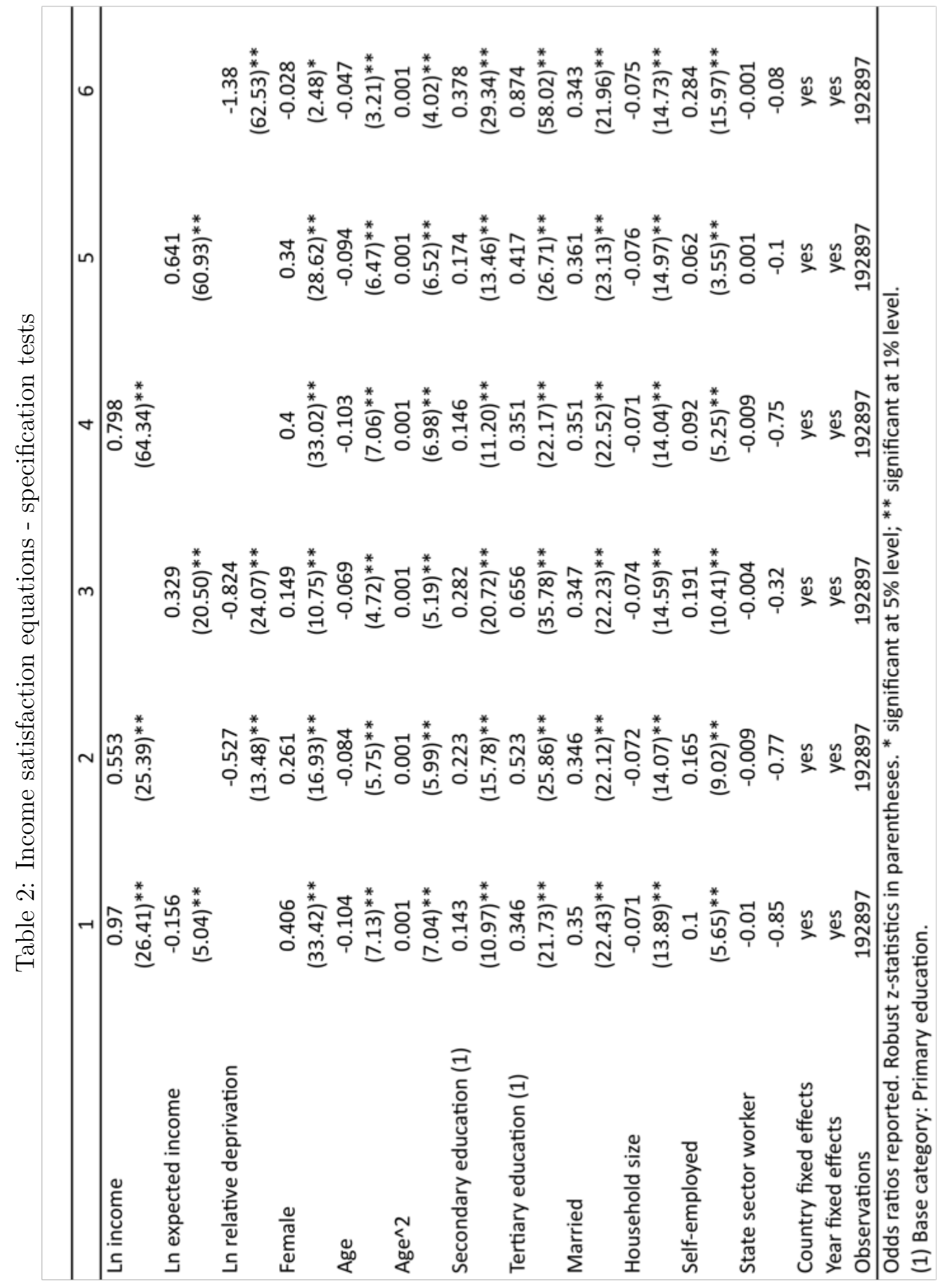


Figure 2: Income Satisfaction and Income Expectation
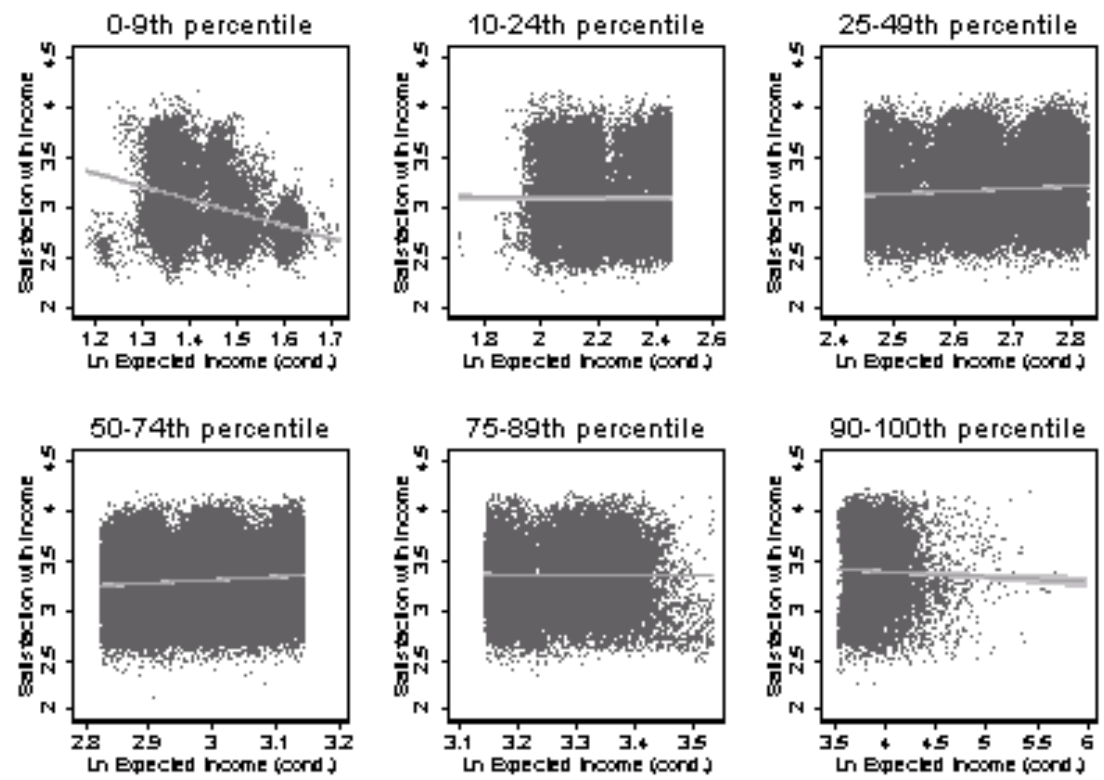

\section{Conclusion}

The paper has proposed a model of income satisfaction composed of two value systems, the 'Ego' system described as the comparison of one own income over time and the 'Alter' system described as the comparison of one own income with the income of others. We constructed aggregated measures for the two systems that would accommodate a wide range of theories on the income-happiness relation drawing mainly on the concepts of relative deprivation and income inequality. Such procedure has also the advantage of reducing the number of regressors in the empirical strategy and overcome in part issues of collinearity.

We find absolute income to sit at the cross-section between the 'Ego' and 'Alter' systems, both theoretically and empirically. This variable emerges as the most important predictor of income satisfaction and contributes to both value systems. Once we control for absolute income, the relation between income satisfaction and 
expected income becomes complex to assess, non linear and overall rather weak.

We also find relative deprivation to play a very important role reducing significantly satisfaction with income. In line with relative income theories, this points to the importance of considering the relative position of individuals in addition to the absolute position. Overall, these findings suggest that the 'Alter' value system (the comparison with others) dominates the 'Ego' value system (the comparison with oneself) in explaining satisfaction with income.

\section{References}

Alesina, A., Di Tella, R., and MacCulloch, R. (2004). Inequality and happiness: are europeans and americans different? Journal of Public Economics, 88:20092042.

Berrebi, Z. M. and Silber, J. (1985). Income inequality indices and deprivation: A generalisation. The Quarterly Journal of Economics, 100(3):807-810.

Chakravarty, S. R., Chattopadhyay, N., and Majumder, A. (1995). Income inequality and relative deprivation. Keio Economic Studies, 32:1-15.

Clark, A., Frijters, P., and Shields, M. A. (2008). Relative income, happiness, and utility: An explanation for the Easterlin paradox and other puzzles. Journal of Economic Literature, 46(1):95-144.

Clark, A. and Oswald, A. J. (1996). Satisfaction and comparison income. Journal of Public Economics, 61(3):359-381.

Crosby, F. (1979). Relative deprivation revisited: A response to Miller, Bolce, and Halligan. The American Political Science Review, 73(1):103-112. 
Davies, J. C. (1962). Toward a theory of revolution. American Sociological Review, 27(1):5-19.

Davis, J. A. (1959). A formal interpretation of the theory of relative deprivation. Sociometry, 22(4):280-296.

Easterlin, R. (1974). Does economic growth improve the human lot? Some empirical evidence. Academic press, New York.

Easterlin, R. (2001). Income and happiness: Towards a unified theory. The Economic Journal, 111:465-484(20).

Festinger, L. (1954). A theory of social comparison processes. Human relations, $7: 117-140$.

Gini, C. (1912). Variabilita' e Mutabilita'. Contributo allo studio delle distribuzioni e relazioni statistiche, volume III of Studi economico-giuridici della Facolta' di Giurisprudenza. Universita' di Cagliari.

Gurr, T. (1968). A causal model of civil strife: A comparative analysis using new indices. The American Political Science Review, 62(4):1104-1124.

Hey, J. D. and Lambert, P. J. (1980). Relative deprivation and the Gini coefficient: Comment. The Quarterly Journal of Economics, 95(3):567-573.

Hirschman, A. O. and Rothschild, M. (1973). The changing tolerance for income inequality in the course of economic development. The Quarterly Journal of Economics, 87(4):544-566.

Karapetoff, W. (1903). On life-satisfaction. The American Journal of Sociology, 8(5):681-686. 
Leibenstein, H. (1962). Notes on welfare economics and the theory of democracy. The Economic Journal, 72(286):299-319.

Nagel, J. H. (1974). Inequality and discontent: a nonlinear hypothesis. World politics, 26:453-472.

Panning, W. H. (1983). Inequality, social comparison, and relative deprivation. The American Political Science Review, 77(2):323-329.

Runciman, W. G. (1966). Relative Deprivation and Social Justice. Reports of the Institute of Community Studies. Routledge and Kegan Paul, London, Boston and Henley.

Schmaus, G., Birch, A., Fisher, K., Frick, J., Haag, A., Schaber, G., Kuchler, B., and Villeret, A. (2003). The Cher project. CHER Working paper 1, CEPS/INSTEAD.

Silber, J. (1994). Horizontal inequity, the Gini index and the measurement of distributional change. Research on Economic Inequality, VI:379-392.

Silber, J. and Verme, P. (2009). Distributional change, reference groups and the measurement of relative deprivation. ECINEQ Working Papers, 136.

Stouffer, S., Suchman, E., DeVinney, L., Star, S., and Williams, R. (1949). The American soldier (1). Adjustment during army life. Princeton University Press.

Verme, P. (2009). Relative labour deprivation and urban migration in Turkey. Journal of Economic Inequality, DOI: /10.1007/s10888-009-9114-7.

Verme, P. (2010). A structural analysis of growth and poverty in the short-term. The Journal of Developing Areas, 43:19-39. 
Verme, P. and Izem, R. (2008). Relative deprivation with imperfect information. Economics Bulletin, 4(7):1-9.

Yitzhaki, S. (1979). Relative deprivation and the gini coefficient. The Quarterly Journal of Economics, 93(2):321-324.

Yitzhaki, S. (1982). Relative deprivation and economic welfare. European Economic Review, 17(1):99-113. 